\section{A prospective policy transfer of learning from abroad in funding long-term care in England}

\author{
Martin Powell \\ HSMC, University of Birmingham, Birmingham, UK
}

Policy transfer and long-term care in England

Received 8 March 2021 Revised 13 May 2021 Accepted 21 May 2021

\begin{abstract}
Purpose - This article explores to what extent the long debate in England over the funding of long-term care (LTC) has involved learning from abroad.

Design/methodology/approach - It draws on Mossberger and Wolman's (2003) framework which proposes criteria for assessing policy transfer as a form of prospective policy evaluation: awareness; assessment and application. The documents examined are the sources cited by the reports that examined funding LTC in England since 1999. The study uses interpretive content analysis in a deductive approach (applying the framework) that focuses on both manifest and latent content.

Findings - It finds that both the reports and the cited studies tend to focus on a fairly narrow range of nations, with most attention on Germany, Japan and Scotland. Most studies broadly do not provide much in the way of a clear rationale, and the level of details provided varies. There is relatively little focus on problems. Aims, objectives and goals are little mentioned in some studies, but they tend to be fairly abstract or "high level." Similarly, there is limited detail on settings. Finally, only a few studies provide a clear recommendation.

Originality/value - It focuses on the neglected topic of the evidence behind reports which are intended to provide recommendations for policy change. The Mossberger and Wolman's (2003) framework has been used in a small-scale but appears to be well-suited for this purpose.
\end{abstract}

Keywords Long-term care, England, Prospective policy transfer, Learning from abroad,

Interpretive content analysis

Paper type Research paper

\section{Introduction}

The UK government, like the governments of many other countries, has highlighted the importance of evidence-based policymaking (EBPM), with learning from abroad frequently recommended in government policy guidance (e.g. Cabinet Office, 1999, 2002; see e.g. Legrand, 2012). However, Legrand (2012) points out that policymaking documents do not consider how policymakers can incorporate evidence, whether domestic or international, into policy. Moreover, few studies have investigated research on both EBPM and learning from abroad (but see e.g. Ingold \& Monaghan, 2016; Legrand, 2012).

The debate on funding long-term care (LTC) in England has been ongoing since the Royal Commission on LTC for the Elderly (RCLTC) was established by the Labour Government in 1997. This article examines the extent to which this long debate has involved learning from abroad. It does not focus on the reports themselves but on the evidence relating to other countries cited in the reports. Specifically, it applies Mossberger \& Wolman's (2003) prospective policy transfer framework to academic articles and texts but is arguably more appropriately applied to evidence cited in reports aimed at exploring options for policy change.

(C) Martin Powell. Published in Fulbright Review of Economics and Policy. Published by Emerald Publishing Limited. This article is published under the Creative Commons Attribution (CC BY 4.0) license. Anyone may reproduce, distribute, translate and create derivative works of this article (for both commercial and non-commercial purposes), subject to full attribution to the original publication and authors. The full terms of this license may be seen at http://creativecommons.org/licences/by/4.0/ legalcode

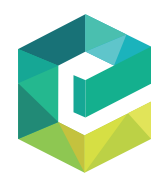

Fulbright Review of Economics and Policy Vol. 1 No. 1, 2021 p. $97-118$ Emerald Publishing Limite e-ISSN: 2635-0181 p-ISSN: 2635-0173 DOI 10.1108/FREP-03-2021-0019 
FREP 1,1

The article is structured as follows. First, it briefly contextualizes the debate around LTC reform in the UK. It then examines policy learning and lesson drawing, focusing on the Mossberger \& Wolman's (2003) framework of prospective policy transfer. Next, it critically analyzes the evidence cited by reports on funding LTC by means of interpretative content analysis, before applying the framework of prospective policy transfer framework to the material.

\section{8}

\section{Long-term care in the UK}

This section provides a brief overview of the debate on funding LTC in England (for more details, see e.g. Bottery, Varrow, Thorlby \& Wellings, 2018; Humphries, 2013; Powell \& Hall, 2020; Wenzel, Bennett, Bottery, Murray \& Sahib, 2018). Some 20 relevant reports on LTC have been compiled by the government, government-appointed commissions and independent think tanks (Table 1).

The UK welfare state was based on a clear divide between the National Health Service (NHS) which was provided according to clinical need and mainly free at the point of delivery, and local government welfare services, which provided or commissioned services such as LTC based on tests of needs and means. In practice, this meant that the Labour Government of 1997 inherited a situation where state support was not available to persons with more capital assets over $£ 16,000$, resulting in them having to might have to sell their homes to pay for nursing or residential or care.

The Labour Government set up the RCLTC, which reported in 1999. The commission was divided with a majority report recommending free personal care (FPC), but two of the 11 commissioners in a "note of dissent" disagreed with this, partly due to its expected high cost to government. On the central recommendation of FPC, the government effectively followed the minority view, arguing that government could spend resources more effectively in other ways. However, the Scottish government did follow the majority view of introducing FPC.

Another attempt at reform was undertaken by the subsequent Labour Government under Prime Minister Gordon Brown, which issued a Green Paper (containing proposals for consultation) and a White Paper (setting out more details for legislation). However, the 2010 general election resulted in a Conservative-Liberal Democrat coalition government.

The coalition government set up the Dilnot Commission, which produced key recommendations of a "cap" to total personal liability for cists, along with changes to the means test. This formed the basis for a government White Paper and then the Care Act 2014, which legislated for a cap of $£ 72,000$, which was far higher, or less generous than Dilnot's proposals. However, highly unusually, the government never put into effect this part of its own legislation, arguing that "austerity" prevented a significant increase in government expenditure.

The general election of May 2015 gave the Conservatives a small majority in Parliament, meaning that they were able to govern without the Liberal Democrats. The Conservative Manifesto for the election promised to implement the cap by April 2016. However, only a few months later, in July 2015, the government abandoned that pledge, stating that reform to any reforms would be delayed to April 2020. However, for the May 2017 general election, Conservative Manifesto provoked significant controversy, as it was widely interpreted that the cap was being dropped. The Conservatives then claimed that this was not the case as nothing had changed. However, this fiasco may have contributed to a loss of support from traditional Conservatives voters which meant that the Conservatives became a minority government. The Conservative minority government then stated that it would abandon plans for a cap. Another general election in 2019 saw a new conservative leader, Boris Johnson, restoring their majority in Parliament. Johnson seemed to regard social care reform as a 


\begin{tabular}{|c|c|c|c|}
\hline Document & Nations & Relevant references & Policy transfer \\
\hline RCLTC (1999a, b) & $\begin{array}{l}\text { Australia } \\
\text { Denmark } \\
\text { France } \\
\text { Germany } \\
\text { Hong Kong } \\
\text { Japan } \\
\text { "Scandinavia } \\
\text { New Zealand }\end{array}$ & $\begin{array}{l}\text { Research Volume 1, Chapter 6: Lessons from } \\
\text { international experience }\end{array}$ & $\begin{array}{r}\text { care in } \\
\text { England } \\
\mathbf{9 9} \\
\end{array}$ \\
\hline Brooks, Regan \& Robinson (2002) & Scotland & - & \\
\hline Hirsch (2005) & $\begin{array}{l}\text { Australia } \\
\text { Austria } \\
\text { Denmark } \\
\text { France } \\
\text { Germany } \\
\text { Japan } \\
\text { Netherlands } \\
\text { Scotland } \\
\text { USA }\end{array}$ & - & \\
\hline JRF (2006) & $\begin{array}{l}\text { Germany } \\
\text { Japan }\end{array}$ & Bell \& Bowes (2006), Glendinning et al. (2004) & \\
\hline $\begin{array}{l}\text { Wanless, Forder, Fernandez, Poole, } \\
\text { Beesley, Henwood \& Moscone (2006) }\end{array}$ & $\begin{array}{l}\text { Austria } \\
\text { France } \\
\text { Germany } \\
\text { Israel } \\
\text { Luxembourg } \\
\text { Netherlands } \\
\text { Scotland } \\
\text { Sweden } \\
\text { USA }\end{array}$ & $\begin{array}{l}\text { Campbell \& Ikegami (2003), Gibson et al. (2003), } \\
\text { Geraedts et al. (2000) }\end{array}$ & \\
\hline Secretary of State for Health (2009) & $\begin{array}{l}\text { Japan } \\
\text { Singapore }\end{array}$ & Glendinning \& Moran (2009), Mehta (2002) & \\
\hline Richard Humphries et al. (2010) & $\begin{array}{l}\text { Australia } \\
\text { Austria } \\
\text { Denmark } \\
\text { Germany } \\
\text { Japan } \\
\text { Netherlands } \\
\text { Scotland }\end{array}$ & $\begin{array}{l}\text { Audit Scotland (2008), Glendinning \& Bell (2008), } \\
\text { Glendinning \& Moran (2009), McCormick et al. } \\
\text { (2009), Sutherland (2008) }\end{array}$ & \\
\hline Dilnot (2011) & No & - & \\
\hline Secretary of State for Health (2012) & No & - & \\
\hline King's Fund Interim Report (2014) & $\begin{array}{l}\text { Appendix C } \\
\text { France } \\
\text { Germany } \\
\text { Japan }\end{array}$ & OECD (2011), Robertson et al. (2014) & \\
\hline Barker (2014) & No & King's Fund Interim Report (2014) & \\
\hline HoCHSCHCLG Committees (2018) & $\begin{array}{l}\text { Germany } \\
\text { Japan } \\
\text { Scotland }\end{array}$ & $\begin{array}{l}\text { Bottery et al. (2018), Curry et al. (2018) } \\
\text { Glendinning \& Willis (evidence) }\end{array}$ & \\
\hline Bottery et al. (2018) & $\begin{array}{l}\text { Germany } \\
\text { Japan } \\
\text { Scotland }\end{array}$ & $\begin{array}{l}\text { Audit Scotland (2008), Bell \& Bowes (2012), } \\
\text { Dickinson \& Glasby (2006), Robertson et al. (2014) }\end{array}$ & \\
\hline Wenzel et al. (2018) & $\begin{array}{l}\text { Germany } \\
\text { Scotland }\end{array}$ & (continued) & $\begin{array}{r}\text { Table 1. } \\
\text { Reports on LTC in } \\
\text { England }\end{array}$ \\
\hline
\end{tabular}




\section{FREP 1,1}

Green (2019)

House of Lords Economic Affairs

Table 1.

\begin{tabular}{lll}
\hline Document & Nations & Relevant references \\
\hline Petrie \& Keohane (2018) & Japan & Curry et al. (2018) \\
Quilter-Pinner \& Hochlaf (2019) & $\begin{array}{l}\text { Scotland } \\
\text { Scotland }\end{array}$ & $\begin{array}{l}\text { Interviews with health and social care leaders in } \\
\text { Scotland; extensive literature review } \\
\text { Audit Scotland (2008), Bell \& Bowes (2012) }\end{array}$ \\
Lightfoot, Heaven \& Gric (2019) & $\begin{array}{l}\text { Germany } \\
\text { Robertson } \text { et al. (2014) }\end{array}$ \\
& $\begin{array}{l}\text { Scotland } \\
\text { Scotland }\end{array}$ & - \\
$\begin{array}{l}\text { Green (2019) } \\
\text { House of Lords Economic Affairs } \\
\text { Committee (2019) }\end{array}$ & $\begin{array}{l}\text { Germany } \\
\text { Sapan }\end{array}$ & Eottery et al. (2018) \\
& Scotland & \\
\hline & &
\end{tabular}

priority, using the opportunity of his first speech to declare that he would solve a problem that governments over the last 20 years or so had been unable to do: "My job is to protect you or your parents or grandparents from the fear of having to sell your home to pay for the costs of care. .. And so I am announcing now. . . that we will fix the crisis in social care once and for all, and with a clear plan we have prepared to give every older person the dignity and security they deserve" (in Powell \& Hall, 2020). However, perhaps due to the coronavirus disease 2019 (COVID-19) pandemic, there does not seem to be any progress on this issue, with no planned legislation revealed in the Queen's Speech of May 2021.

In short, there seems to have been little change since RCLTC of 1999, suggesting a version of the main plot of the film "Groundhog Day," where recommendations made by some 20 government documents and many more proposals from think tanks have not resulted in any significant reform. The main reason for the policy gridlock appears to be cost. Different governments have stressed the problem of introducing new insurance payments or raising taxation (particularly in a period of austerity) to transfer costs from the individual to the public purse by either making care free or imposing a cap. The most obvious example was the strange decision of the Conservatives to not introduce the provisions of their own Act of Parliament in 2014 (Powell \& Hall, 2020).

\section{Learning from abroad}

Reviews of policy learning (e.g. Bennett \& Howlett, 1992; Grin \& Loeber, 2007; Heikkila \& Gerlak, 2013) have explored broadly similar questions. For example, an early and well-cited review examined "who learns?" (the subject of learning), "learns what?" (the object of learning) and "to what effect?" (the results of learning). The reviews examine "lesson drawing," a term coined by Rose (1991, 1993; see de Jong, 2009). According to Rose (1991, p. 3), "The process of lesson-drawing starts with scanning programmes in effect elsewhere, and ends with the prospective evaluation of what would happen if a programme already in effect elsewhere were transferred here in future." However, it has also been argued that the literature on policy transfer and lesson drawing has paid limited attention to learning, and particularly ignores the phases of learning of information acquisition, translation and dissemination (Heikkila \& Gerlak, 2013; Ingold \& Monaghan, 2016).

Wolman \& Page (2002) examine policy transfer as an instance of policy learning by adopting a communications and information framework, exploring the neglected elements of how information is processed, framed and assessed. They stress that most policy transfer studies focus on information receivers rather than providers. In contrast, they focus on sources of information (their Table 2), with the most frequent ones being 


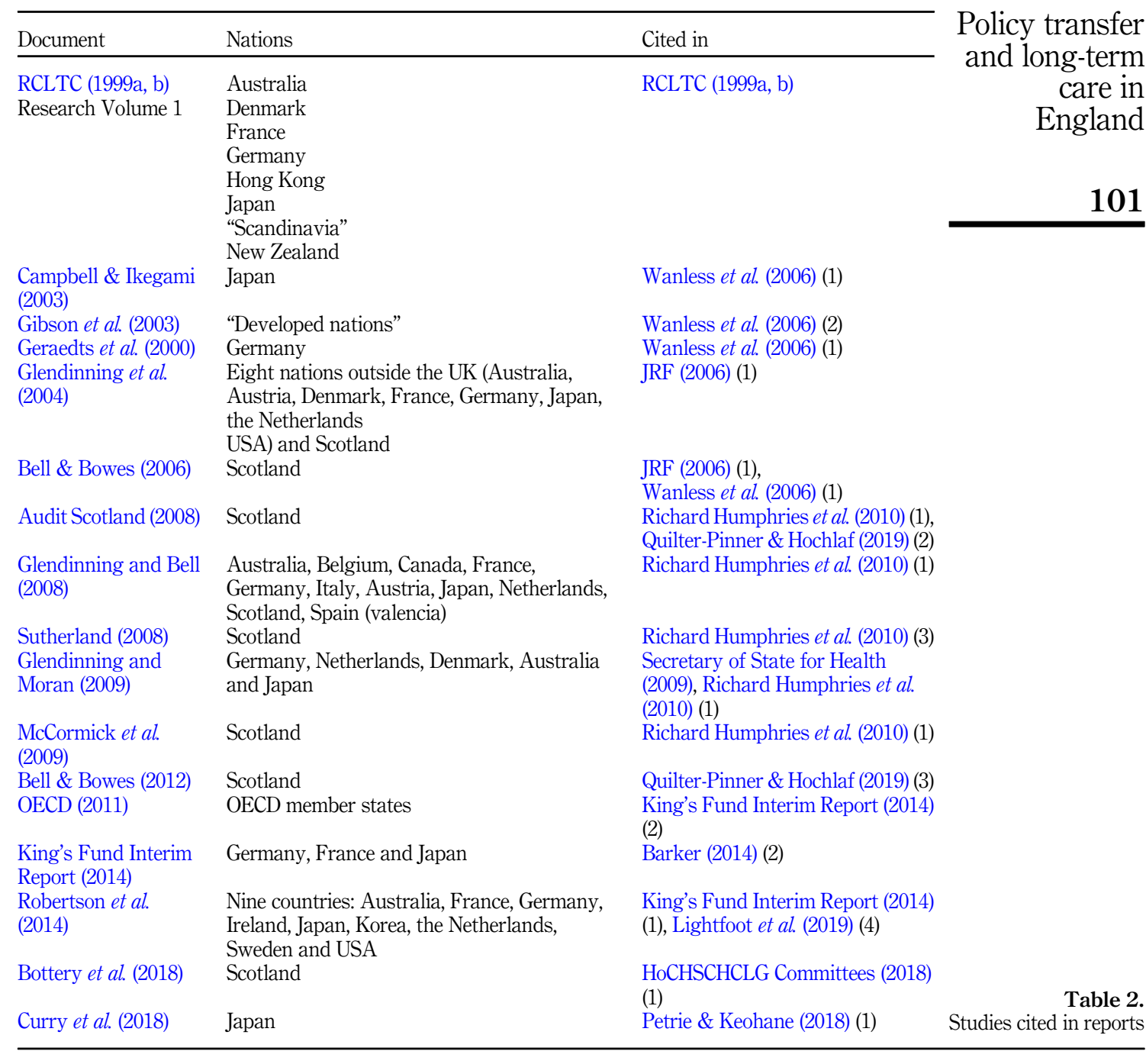

government publications, conversations with officials, good practice guides, and practitioner journals and the least frequent ones being conversations with researchers, academic journals and study tours. Similarly, the most useful sources are conversations with officials, government publications, good practice guides and practitioner journals, while the least useful are study tours, conversations with researchers and academic journals. They note the broad similarity between the lists, as people are likely to use sources they have found useful.

Mossberger \& Wolman (2003) present a framework of prospective policy evaluation, a term coined by Rose $(1991,1993)$, which examines attempts by policymakers to evaluate the effect of a policy before it is implemented. They propose criteria for prospective policy evaluation of awareness, assessment and application (see below). 


\section{FREP 1,1}

\section{Method}

The reviewed documents are sources cited by the reports examining the funding of LTC in England since the RCLTC $(1999 \mathrm{a}, \mathrm{b})$ report. The first step in this process is to examine the reports to determine if they discuss learning from abroad, using keywords, such as nations (e.g. German*, Scot*), international, learning and lessons (Table 1).

Some reports, such as Dilnot (2011), do not draw on international material and are, therefore, excluded from further analysis. Similarly, reports such as Hirsch (2005), which mention other nations but with no references, are excluded from further analysis.

The second step is to examine the cited material (Table 2) to uncover points made about other countries. Cited material is examined only if it is explicitly linked to learning from other countries. For example, Wanless et al. (2006) cite Brodsky, Habib \& Mizrahi (2000), whose work seems to have some face validity but appears to be a passing reference and not linked with lessons from abroad; thus, it is not included in Table 2. Similarly, the Secretary of State for Health (2009) cites Mehta (2002) on Singapore but this refers to a partnership scheme and the legal obligation placed children to pay for their parents' care. As this does not appear to have been advanced as a policy option in England, it is not included in Table 2.

Many reports do not appear to make much use of the international material. For example, Joseph Rowntree Foundation (JRF, 2006) only draws on Bell \& Bowes (2006) and Glendinning, Davies, Pickard \& Comas-Herrera (2004) in "Box 2: two 'big bangs' (Germany, Japan) and Scotland's small bang." Some reports do not appear to make much use of their own commissioned material, such as Wanless et al.'s (2006) Background Papers, "Free personal care in Scotland," "Scotland: care trends" and "Funding options for older people's social care," to learn from abroad. It points out that more details of the various funding systems in Organisation for Economic Co-operation and Development (OECD) countries can be found in a background paper in the Appendix, but it does not appear to inform the analysis to much extent. Similarly, Glendinning \& Moran's (2009) research was conducted in preparation for the Green Paper on social care, but it is only used at one point by the Secretary of State for Health (2009) and by Richard Humphries et al. (2010).

The method involves interpretive content analysis (Drisko \& Maschi, 2016). In particular, it uses a deductive approach that draws on both manifest and latent content. The main aim of a deductive approach is to test a previous theory, with keywords derived from the relevant literature, namely the framework of prospective policy transfer (below). While manifest content analysis searches for a particular word or content, latent content analysis involves discovering underlying meanings of the words or content.

\section{Prospective policy evaluation for funding long-term care in England}

This section adopts Mossberger \& Wolman's (2003) criteria of prospective policy transfer to examine the sources cited by reports on funding LTC.

\section{Awareness: scope of information}

This section explores "Scope of Information," which is the first component of the criterion of "Awareness." In particular, it focuses on the sources of and justifications for lessons (see Table 2). Mossberger \& Wolman (2003) point out that policies considered for transfer should have addressed a similar problem in the original nation, or that the nation has important similarities, and has seen to be successful.

The RCLTC (1999a, b) Research Volume discusses various countries and provides detailed descriptions of four countries visited by some commissioners: Germany, Australia, New Zealand and Denmark. Geraedts, Heller \& Harrington (2000) focus on the German 
Long-Term Care Insurance (LTCI) Act of 1994. Campbell \& Ikegami (2003) focus on the Japanese LTCI program of 2000 and indicate that the problems that led Japan to develop its new LTCI program were not dissimilar to those in other nations but may have been more intensely felt.

Gibson, Gregory \& Pandya (2003) discuss a large number of "developed nations," stating that the selection of country-specific examples is somewhat subjective and depends heavily on the availability of sufficient information. They focus broadly on the rapidly aging populations of European nations and Japan. However, they also present some examples from several Commonwealth nations, such as the Australia, Canada and the UK, in order to illustrate the diverse nature of LTC policies.

Glendinning et al. (2004) examine arrangements for funding LTC in eight countries outside the UK, selected to reflect a diverse range of funding arrangements or because they had recently implemented major reforms to LTC funding. Scotland is included as the one UK country to recently introduce FPC. Bell \& Bowes (2006) explore financial care models in Scotland and the UK, focusing on the introduction of free personal and nursing care (FPNC) in Scotland before turning to wider lessons for the UK as a whole in designing policies to provide care to older adults. Similarly, Audit Scotland (2008) examines Scotland with a focus on financial issues.

Glendinning \& Bell (2008) illustrated with examples from Scotland, European and other developed countries. They discuss Australia, Austria, Belgium, Canada, France, Germany, Italy, Japan, Netherlands and Spain (Valencia). Sutherland (2008) provides a review of Scotland commissioned by the chair of the RCLTC (1999a, b). Glendinning \& Moran (2009) represents a department of health funded report that summarizes experiences of a few nations that have reformed funding and delivering of LTC. The selection criteria for these countries include active debates, reforms in funding or delivering social care and information in the form English-speaking experts informants. This resulted in the inclusion of Germany, the Netherlands, Denmark, Australia and Japan.

McCormick, McDowell \& Harris (2009) present research from a larger study examining devolution and old age in the UK, with a short chapter (about four pages) on Scotland including material on LTC. The OECD (2011) focuses on its member states but does not state how those with more detailed discussions were selected. Bell \& Bowes (2012) examine Scotland in a chapter of a book published in the United States.

The King's Fund Interim Report (2014) includes a section on "England and the United Kingdom's place internationally," with details in Appendix C, which discusses how much better off other countries, such as Germany, France and Japan, are, supported by recent examples of changes in social care funding. In a background paper on the international context prepared for the RCLTC, Robertson, Gregory \& Jabbal (2014) profile nine countries that have adopted a range of approaches to provide health and social care. What nearly all these countries have in common is a recent reform to their system of health or social care (with "interesting and novel reforms") or one in progress. The selections were based on international health and social care systems by the authors and recommendations from experts. Bottery et al. (2018) explore five approaches to funding social care for older adults in England that were chosen to reflect solutions commonly raised in the debate around social care funding. They largely reflect recent policy discussion within England, but one of the options focuses on FPC in Scotland.

Curry, Castle-Clarke \& Hemmings (2018) justify focusing on Japan by arguing that while Japan is very geographically and culturally different from England, its demographic, economic and social trends make it a source of valuable policy learning. It is important to study the experiences and lessons of countries that are a few steps ahead, and Japan is an exemplary country that has demonstrated the possibility of achieving fundamental reform.
Policy transfer and long-term care in England 
FREP 1,1
Table 3 provides a summary of the application of prospective policy transfer criteria. Regarding the scope of information, a rather narrow range of countries is represented, including Germany (7 instances), Japan (7 instances) and Scotland (7 instances) (see Table 2). Some studies provide no clear justification for their choice of countries. Those that do provide some rationale include similar problems (e.g. Campbell \& Ikegami, 2003), recent reforms (e.g. King's Fund Interim Report, 2014; Curry et al., 2018), a range of approaches (e.g. Robertson et al., 2014), "purposively selected countries" (Glendinning \& Moran, 2009) and a "diverse range" of criteria (e.g. Glendinning et al., 2004).

\section{Awareness: adequacy and accuracy of information}

The second component of awareness is "Adequacy and Accuracy of Information." In their discussion, Mossberger \& Wolman (2003) explore the accuracy of information about goals, policy design and policy operation. However, this seems to have some overlap with their focus on other components (below) such as similarities in the problems, goals and policy performance, so this discussion focuses on the level of detail in the provided descriptions. In particular, Mossberger \& Wolman (2003) argue that borrowing countries generally seemed to have fairly accurate and detailed knowledge of the programme. However, they point out that information tended to be gathered through study visits and conferences, and more formal evaluations of programmes and more critical perspectives were less evident.

Although, in principle, adequacy and accuracy appear to be two distinct dimensions, in practice, they seem to blend into one for two reasons. First, it is unclear how accuracy can be judged, as it implies a comparison against some external yardstick, and it is difficult to choose and justify this "accurate" picture against which to evaluate the accounts. Second, in many cases, accuracy may be seen as related to the level of detail, with very broad brush accounts necessarily lacking accuracy. Most of the material below largely focuses on the level of detail provided in the studies.

Some sources focus on one nation, and so provide "depth", while others cover a number of nations, and so provide "breadth". The RCLTC (1999a, b) report provides a significant level of detail on the four countries visited with some evidence from other nations (e.g. the USA). Geraedts et al. (2000) provide a significant level of detail on the German LTCI scheme, and Campbell \& Ikegami (2003) provide a good level of detail from other authors who have analyzed Japan's LTCI. Gibson et al. (2003) cover many “developed nations" in some 30 pages or so. There is some significant detail regarding nations featured in a number of points, such as Germany, but very little detail on others mentioned in passing only once or twice, such as Greece. At one point, they provide "thumbnail sketches" of Austria, Germany, the Netherlands and Japan.

Glendinning et al. (2004) review literature published in English on LTC arrangements in selected countries, with accuracy checked with policy experts in each country, who were also asked to add details of any very recent developments or debates. The criteria of evaluation for LTC funding arrangements were derived from a seminar of academic and policy experts. The report contains a comprehensive bibliography including material in the language of some of the nations studied.

Bell \& Bowes (2006), who focus on LTC in Scotland in other studies (Bell is an expert who was invited to support Sutherland's review), discuss Scotland in extensive detail in a document of over 120 pages. Audit Scotland (2008) examines Scotland, focusing on financial issues, including an analysis of national data, surveys of the 32 councils and of independent care home providers, and focus groups with older people and care providers. It states that this study complements the work of Lord Sutherland, who was commissioned by the Cabinet Secretary for Health and Wellbeing to carry out an independent review of the policy (Sutherland, 2008). 


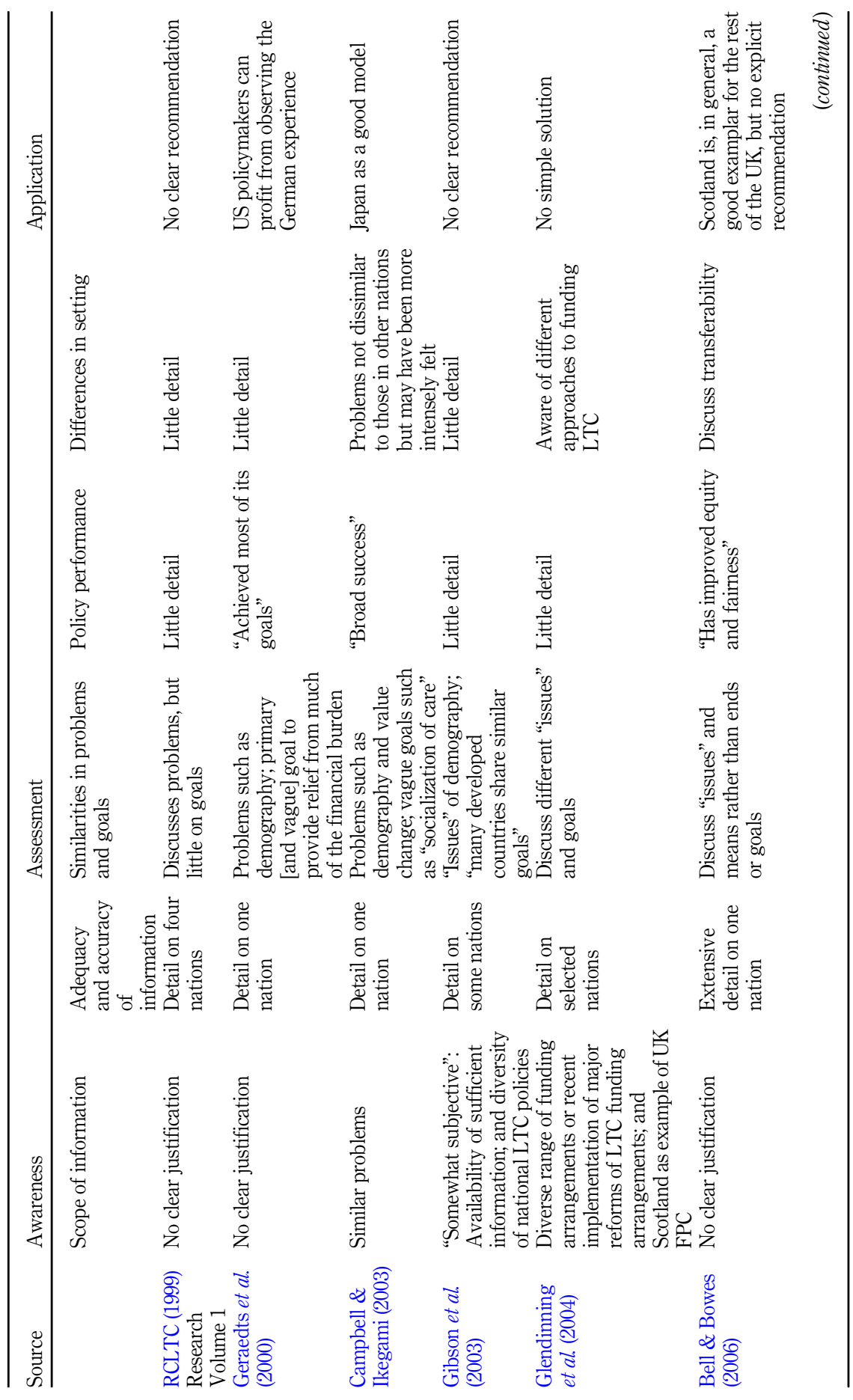

Policy transfer and long-term care in England

105

Table 3. Prospective policy transfer criteria 


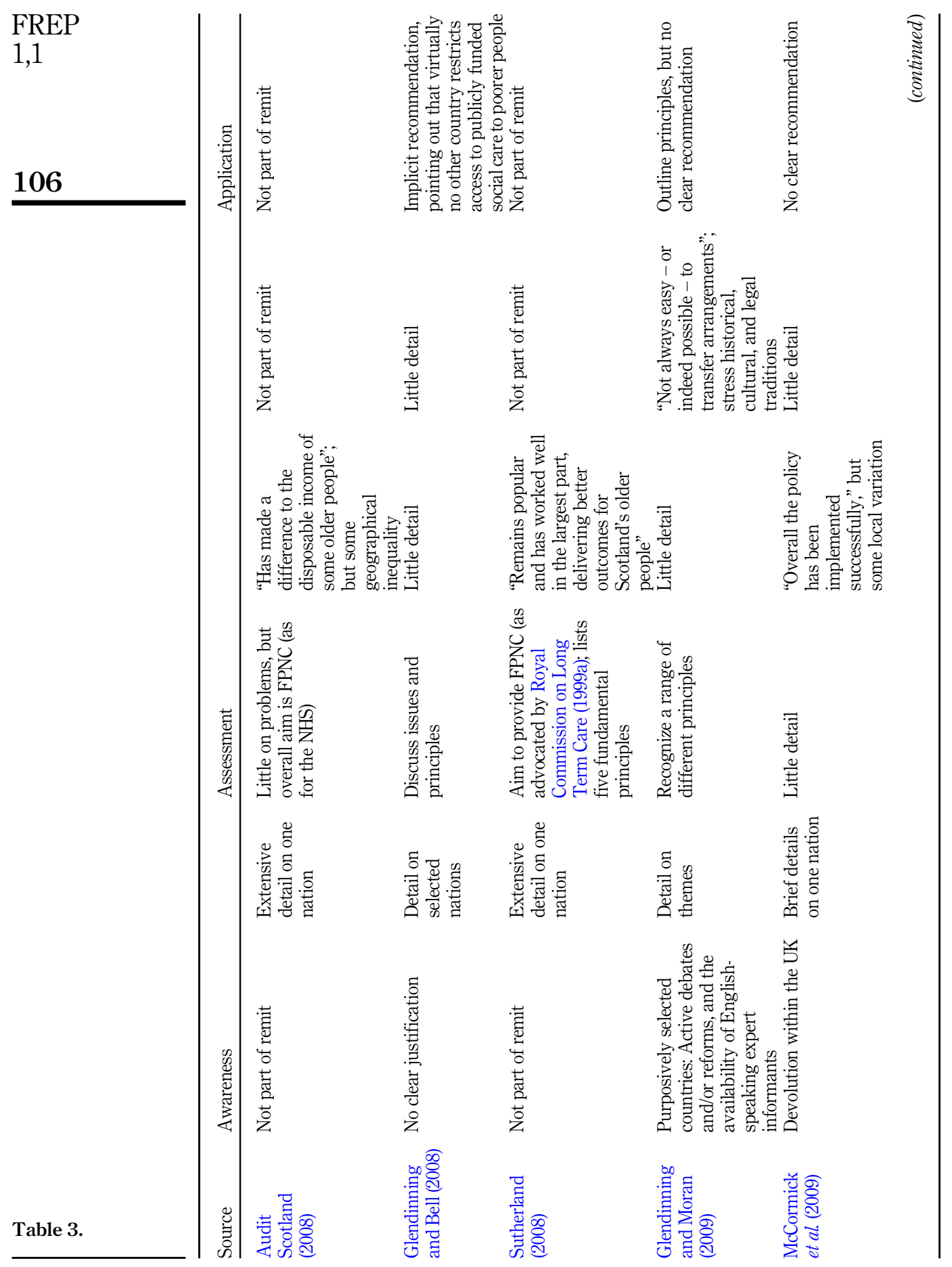




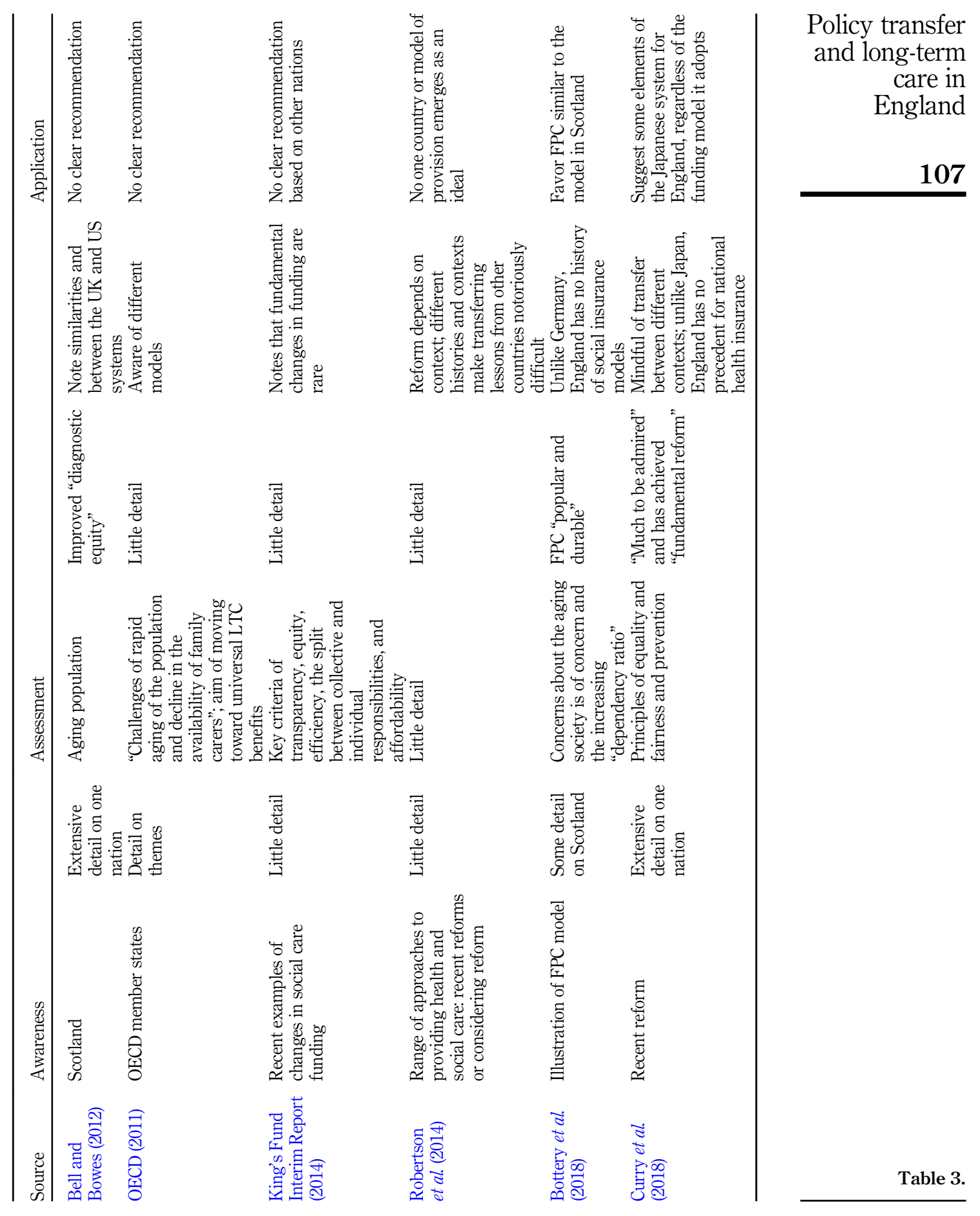


FREP 1,1
Glendinning \& Bell (2008) discuss key features of social care and principles that should underpin the funding and organization of social care and support in England, illustrated by lessons and examples from other countries. Sutherland (2008) provides a detailed evaluation of the Scottish FPSC policy in some 90 pages, including how it has measured up to the original vision. McCormick et al. (2009) present research that forms part of a wider study examining devolution and old age in the UK, with a short chapter on Scotland of about four pages including material on LTC.

Glendinning \& Moran (2009) examine selected nations that have reformed funding and delivering of LTC. Nations are examined in individual chapters, including a short summary of the current arrangements, recent reforms and current debates about the funding and organization of care in each country. Each chapter has a common structure: background and context, funding, organization and eligibility, cost containment measures and growing funding pressures, and options for reform.

The OECD's (2011) study comprises over 300 pages presented in thematic chapters: the growing demand for LTC in aging societies, the role of family carers, employment conditions in formal LTC labor markets, public and private coverage schemes for LTCs, and financing policies to improve access while controlling costs. It uses a mix of quantitative and qualitative methods.

Bell \& Bowes (2012) provide a full account of Scottish FPC policy, with some policy lessons for the United States from the Scottish experiment in FPC. The King's Fund Interim Report (2014) provides little detail on other countries beyond pointing out the low expenditure on LTC in the UK and that other countries have introduced recent policies. Robertson et al. (2014) profile nine countries that take a range of approaches to providing health and social care. However, they focus more attention on health than social care systems. The country profiles generally include context, entitlements, funding, delivery and key issues. Bottery et al. (2018) focus strictly on Scotland in detail, mentioning other nations, such as Germany, only in passing.

Curry et al. (2018) present a report of over 50 pages based on a visit to Japan. They carried out a literature review and held discussions with academics and other system experts. They visited two municipalities in Tokyo, and five care delivery services. In addition, they had consulted documents from and held meetings at the Ministry of Health, Labour and Welfare.

Table 3 indicates that studies focused on one nation or long reports can necessarily provide a greater level of accuracy and detail than studies that attempt to cover numerous nations in relatively few words. However, it is difficult to provide the amount of detail required to fully understand a complex policy area even by providing detailed material on one nation.

\section{Assessment: similarities in problems and goals}

This section explores the first component of "Assessment", namely "Similarity in Problems and Goals". Mossberger \& Wolman (2003) argue that potential adopters should assess the similarity of problems and goals in exporting and importing nations, pointing out that one major reason for unsuccessful policy transfer is to transplant a policy intended to solve a particular problem with an associated policy goal in the originating country to solve a different problem, with a different goal in the borrowing country.

While the RCLTC (1999a, b) discusses problems, it says little about goals. Geraedts $e$ al. (2000) discuss problems such as demography, stating that Germany, to an even greater extent than most industrialized countries, is facing a tremendous growth of its elderly population. They claim that the prime German LTCI goal is to reduce the financial burden of long-term disability and illness, but another goal is to promote the creation of a new infrastructure for formal LTC services, given that many older people who require LTC tend to be cared for by relatives. However, these are fairly abstract and high-level goals, which are difficult to operationalize in any evaluation. 
Campbell \& Ikegami (2003) discuss the objectives of Japan's LTCI scheme, but they seem too vague to be regarded as specific goals, such as the "socialization of care" and the sharing of costs by elders via insurance premiums as well as co-payments. Problems include the world's most rapid growth of the elderly population, decline in traditional sources of care, strains on other social programs and value change.

Gibson et al. (2003) tend not to use the term "problem," although they note that all industrialized nations are grappling with issues of access, cost and quality in LTC services. They discuss issues of demography and aging and stress the similarity in broad goals, stating, "in summary, many developed countries share similar goals with respect to the delivery and financing of LTC." They also note a WHO publication highlighting that both equity and efficiency are critical policy objectives in funding systems for health and LTC.

Glendinning et al. (2004) note that other developed countries and many developing ones are grappling with issues of scope, access, cost and quality of LTC. They focus particularly on equity; efficiency and effectiveness; dignity, choice and independence for older people; and political and economic sustainability. They discuss policy goals, such as equity, concluding that it is it must be noted that other systems may reflect different objectives. They argue that in order to learn lessons for the UK, it is necessary to examine the perceived strengths and weaknesses of both the UK arrangements and other nations in terms of specific objectives. It is particularly necessary to consider if other nations attach different values to the stated goals of the UK.

Bell \& Bowes (2006) do not discuss problems per se but outline issues, such as demography, illness, affluence, the balance of care and informal caring. Similarly, they tend to stress the means of FPC rather than the underlying goals or objectives of the policy. There is also little in Audit Scotland (2008) on problems, but it does discuss goals. It states that there is a clear overall aim for the FPNC policy, which is making personal and nursing care free of charge to all older people assessed as needing it, which compares to free care in the NHS. However, there are ambiguities in both the legislation and guidance in several key areas. Glendinning \& Bell (2008) discuss issues such as balancing private and public responsibilities, universality and different dimensions of equity (e.g. diagnostic equity, spatial equity and intergenerational equity). They conclude that a reform programme may not be able to meet all principles, and certainly not to an equal extent. Sutherland (2008) notes that the policy to provide personal and nursing care in Scotland, which is free at the point of delivery and is assessed according to need, was modeled on the RCLTC (1999a, b). Furthermore, the Scottish executive agreed with the underpinning principles of fairness and equity which underpinned the RCLTC's recommendations. Sutherland's recommendations concern six fundamental principles. FPNC should be an entitlement for everyone assessed as needing this level of care and support; similar principles to the NHS; wider provision of care as a responsibility shared between the state and individuals; an established and mainstream part of LTC funding rather than as an "optional extra"; a fair and equitable system; and transparency about the resources underpinning the system, and entitlements and responsibilities of individuals. McCormick et al. (2009) do not discuss problems or goals.

Glendinning \& Moran (2009) note that evidence from other nations can shine a light on principles and assumptions on which funding and delivery arrangements could be based. The OECD (2011) notes the "challenges" of a rapidly aging population and decline in the availability of family carers. It argues that there are equity and efficiency reasons for moving toward universal LTC benefits, irrespective of the financing model. Universal LTC entitlement improves protection against catastrophic care costs, but this not does mean that all LTC should be free.

Bell \& Bowes (2012) note that the UK and US systems have similarities but also some important differences. Like many countries, the UK has an aging population. The King's Fund Interim Report (2014) proposes key criteria for assessing the options for a new settlement: affordability, equity, efficiency, transparency and a split between collective and
Policy transfer and long-term care in England 
FREP 1,1

individual responsibilities. It argues that the problems of the current settlement are systemic, stressing issue with alignment and equity. It notes that "sixty-six years on: 2014 is not 1948": the world has changed in terms of greater longevity and an altered burden of disease. Robertson et al. (2014) do not seem to consider problems or goals in any significant detail. Bottery et al. (2018) point to the problem of long-term demographic trends and concerns about the aging society and increasing "dependency ratio." They examine the advantages and disadvantages of their five different models but not clearly against clear system goals.

Curry et al. (2018) note that LTCI in Japan is based largely on the principles of equality and fairness and is a needs-based system providing care to all, regardless of wealth or income. The vision for 2025 for the Japanese government aims to place prevention at the heart of society.

As Table 3 shows, several studies underline the problem of demography or an aging population (e.g. Geraedts et al., 2000). Few studies provide precise goals, although two studies on Scotland highlight that the overall aim is FPC (as for the NHS) (Audit Scotland, 2008; Sutherland, 2008). Some studies discuss "issues and principles" rather than aims or goals (e.g. Curry et al., 2018; Glendinning \& Moran, 2009). Gibson et al. (2003) claim that "many developed countries share similar goals."

\section{Assessment: policy performance}

The second component of "Awareness" is "Policy Performance." Clearly, it is of little value emulating a policy that is regarded as unsuccessful. However, Mossberger \& Wolman (2003) claim evaluating success is problematic due to problems of selection bias, as information tends to be collected more from advocates of the programme rather than its critics. They warn that this unsystematic and unstructured means of gathering information may lead to policymaking by anecdote rather than by analysis.

The RCLTC (1999a, b) is scarce on policy performance details. Geraedts et al. (2000) discuss the "preliminary results" of LCTI in terms of benefit recipients, LTC expenditures, LTC infrastructure and financial status of the system. They claim that Germany's new social and private LTC insurance system seemed to achieve most of its goals in its initial years of operation. For example, after one year of partial operation followed by three years of full operation, the new system showed financial stability and access for persons requiring LTC improved so substantially that there was excess capacity in institutional care.

Glendinning et al. (2004) particularly focus on equity; dignity, choice and independence for older adults; efficiency and effectiveness; and economic and political sustainability but provide little detail on these issues. Bell \& Bowes (2006) indicate that assessing the specific impact of FPC in Scotland is complicated by wider changes in a range of care policies. They focus on the effects of the policy, particularly its financial effects, on both local authorities and citizens, including the balance of care, costs of care, equity and fairness, and consumer perspectives. They conclude that FPNC has improved equity and fairness, particularly for those with conditions such as dementia, and for those of modest means, who had previously found charges particularly burdensome. Moreover, they claim that there has been a blurring of the artificial boundaries between health and personal care. Audit Scotland (2008) concludes that FPNC has made a difference to the disposable income of some older people, but it is not apparent that it has made a difference to older people on lower incomes, who would have received personal and nursing care services free in any case. Although FPNC is a universal policy, differences between eligibility criteria and waiting lists of councils remain. Consequently, service levels for older people may vary according to where they live. However, there were many other changes significant changes and developments in health and social care at the time of the introduction of FPNC. This makes it difficult to evaluate the impact of the policy in isolation from other changes, even if clear intended outcome measures were not lacking. 
Glendinning \& Bell (2008), who cover various countries in roughly 12 pages, do not discuss each country's policy performance in detail. Instead, they provide some vignettes on different issues, such as intergenerational equity in Germany. Sutherland (2008) examines the impact of Scotland's FPNC policy, including how it measures up to the original vision, an economic analysis, and concludes that despite some practical difficulties in its formative years, the FPNC policy remains popular and has worked well for the most part, delivering better outcomes for Scotland's older people. Glendinning \& Moran (2009) do not seem to give much in the way of evaluation in their national chapters. McCormick et al. (2009) note that local variations in the implementation of Scotland's FPC policy may be serving to maintain or create new inequalities between different parts of Scotland. Moreover, reviews by Sutherland (2008) and Audit Scotland (2008) find that the policy has been implemented successfully overall. There seems to be little on policy performance in the OECD (2011) report.

Bell \& Bowes (2012) provide little by way of assessing policy performance, other than stating that the obvious drawbacks are the policy's future affordability given demographic change and the extent to which it provides a subsidy to the relatively rich, who could afford to pay for their care. However, they point to increased diagnostic equity between conditions requiring long-term health interventions (eg cancer) and those requiring LTC (eg dementia). The King's Fund Interim Report (2014) provides some assessment of their five policy options but little direct assessment of other countries. The Appendix "Is the grass elsewhere?" does not really provide a clear answer to where the grass is greenest. Robertson et al. (2014) focus more on health but state that most countries provide more comprehensive coverage of healthcare than social care needs, but the gap between the two is generally less stark than in England. Evaluation tends to be rather limited. For example, the report claims that the Korean scheme has received positive initial feedback with high reported levels of satisfaction. However, criticisms include a limited supply of residential care providers, particularly in urban areas around Seoul, which seems to cause long wait times. Bottery et al. (2018) explore five approaches to funding social care for older adults in England, discussing the advantages and disadvantages of the approaches. However, this only clearly maps onto a case like FPC in Scotland, where they claim that the model seems to be popular and durable, which has led to it being expanded to adults of working age.

Curry et al. (2018) state that there is much to admire about Japan's implementation of a national comprehensive care service. They claim that a key success for Japan, in contrast to England repeated failures, has been in ensuring public support through transparency and consistency, and that Japan has achieved fundamental reform.

As Table 3 reveals many of the sources provide little detail on policy performance (e.g. OECD, 2011). Some studies explain particular criteria. For example, Bell \& Bowes (2012) report improved diagnostic equity, while Bell \& Bowes (2006) claim that reforms in Scotland "improved equity and fairness." However, other studies are rather vague, for example, referring to "broad success" (Campbell \& Ikegami, 2003) or "achieved most of its goals" (Geraedts et al., 2000).

\section{Assessment: differences in setting}

The second component of "Assessment" is "Differences in Setting," which explores contextual differences between the origin and destination nations. It is clear that there are many contextual features, such as culture, which may mean that a policy that is successful in one setting may not be successful in another (Mossberger \& Wolman, 2003).

The RCLTC (1999a, b) discusses different systems but offers little regarding different settings. Geraedts et al. (2000) state little about settings beyond stressing common issues, such as demography. Campbell \& Ikegami (2003) state that the problems that led Japan to its new LTCI program were not dissimilar to those in other nations but may have been more
Policy transfer and long-term care in England 
FREP 1,1

intensely felt. Moreover, unlike Germany, where LTCI covers disabled people of all ages, Japan focused on elderly people, with the main reason being that the "problem of the ageing society" had been at the top of the policy agenda for years.

Gibson et al. (2003) are clearly aware of the importance of different settings in their thumbnail sketches. For example, they differentiate between universal coverage in many countries versus selective or means tested services (e.g. England, the USA), but there is little analysis of how different settings may matter for implementation or outcomes.

Glendinning et al. (2004) point out that there are at least five broad approaches to funding LTC, including national and local taxation and insurance schemes with varying employer contributions. In a discussion of "equity in raising resources - lessons for the UK," they note that that the progressivity of the mechanisms for raising revenue partly influences the equity implications of approaches to LTC funding. This means that debates about the funding of LTC need to discuss both mechanisms to raise and allocate revenue.

Bell \& Bowes (2006) indicate some "lessons for transferability" and issues of making comparisons. They claim that Scotland is a good exemplar for the rest of the UK, but note the greater prominence of its public sector. Moreover, they point out that Scotland displays more variation between local authority areas compared to the rest of the UK. One of the few major differences in care provision is that the private market is significantly larger in England than in Scotland. However, they claim that many of the lessons learned in Scotland will be broadly applicable to the rest of the UK. Owing to the terms of reference that Audit Scotland (2008) uses, it does not consider settings and differences. Glendinning \& Bell (2008) are clearly aware of the importance of settings (e.g. cash versus care, national versus local, universal versus means-tested) but are unable to discuss these issues in much detail in their brief report. Similarly, the remit of Sutherland (2008) did not ask it to consider differences in settings, although it stressed that the policy was modeled on the RCLTC (1999a, b), chaired by Sutherland.

Glendinning \& Moran (2009) point out that the difficulty of transfer from one nation to another. They argue that LTC arrangements are often embedded in the distinctive legal, cultural, and historical traditions of particular countries. However, comparisons with other countries may be useful to identify underlying principles and trajectories of change. McCormick et al. (2009) do not comment on settings apart from the divergence in policy with England. The OECD (2011) is evidently aware of very different models, such as universal coverage and "safety-net" or means-tested schemes (UK, excluding Scotland; the USA). It notes that OECD countries rely on different approaches to raise funds to pay for LTC coverage, and pressures on LTC systems are expected to grow in the future. Bell and Bowes (2012) note similarities between the UK and US systems (e.g. aging population, means-tested system) as well as some important differences.

The King's Fund Interim Report (2014) pays little attention to settings. It does note examples of more radical reform in funding structures such as Germany, France and Japan. However, it is concerned that such social insurance schemes might be in conflict with its goal of producing a more seamless health and social care system. It continues radical changes, such as England changing from a tax-funded system to a social insurance one, that are rare and difficult, and is concerned that significant benefits would not be guaranteed. Robertson et al. (2014) profile nine countries that take different approaches to health and social care provision, but most of these have recently reformed or are currently reforming their system of health or social care. However, they note the difficulties of transferring lessons from other countries with different histories and contexts. Major reforms are possible but take time and are dependent on the local context. Bottery et al. (2018) note that unlike Germany, England has no history of social insurance models and may be more likely to introduce a specific tax. Moreover, they appear to favor the Scottish system. 
Curry et al. (2018) point out that while geographically and culturally, Japan is very different from England, the former can be a source of valuable policy learning for the latter. They are aware of the complexities of international comparisons and the problems of transfer. Therefore, they do not attempt to make direct comparisons between England and Japan, but rather stress the elements of the Japanese system that could be incorporated into English policy. They note that Japan is one of several countries that have demonstrated the possibility of achieving fundamental reform. However, England, unlike Japan, has recent mechanism for national health insurance, and so this may not be regarded as an appropriate mechanism.

As Table 3 shows, many studies provide little detail on differences in settings. However, Glendiing \& Moran (2009) note that it is "not always easy - or indeed possible - to transfer arrangements," and emphasize historical, cultural and legal traditions. Robertson et al. (2014) argue that reform depends on context: different histories and contexts make transferring lessons from other countries notoriously difficult. Bottery et al. (2018) underline that unlike Germany, England has no history of social insurance models. Curry et al. (2018) are "mindful of transfer between different contexts," remarking that "unlike Japan, England has no precedent of national health insurance."

\section{Application}

The final criterion examines whether decisionmakers in the borrowing nation draw on all relevant information in the decision-making or application process (Mossberger \& Wolman's, 2003). However, the case here does not concern government decision-making but rather focuses on whether clear recommendations to government are made.

The RCLTC (1999a, b) Research Volume does not seem to provide a clear recommendation. Geraedts et al. (2000) conclude that in view of the promising start of the new LTCI system in Germany, US policymakers who weigh the feasibility of devising a social insurance approach for LTC and debate its possible shape and practicality can profit from observing the reported German experience. Campbell \& Ikegami (2003) argue from the perspective of the Japanese case that creating a comprehensive system, compared with the piecemeal approach to LTC common around the world, offers the best chance for controlling costs while expanding access and assuring quality care for frail older adults and their families. Gibson et al. (2003) do not provide a clear recommendation, although they seem to prefer universal to selective systems.

According to Glendinning et al. (2004), an important lesson is that there is no simple solution; trade-offs are inevitable and other countries have had to make difficult decisions similar to those facing the UK. At the end of each chapter, they present lessons for the UK for each issue. Moreover, in the concluding chapter, they write that sometimes difficult choices exist, without any clear simple technocratic solutions. They state that none of the countries in their study introduced a funded insurance scheme for LTC. They ask numerous questions but provide few answers. They stress the important of different national objectives. However, they argue that it would be possible to consider elements of other approaches to funding LTC, which may increase the effectiveness, efficiency, fairness and sustainability of the UK system.

Bell \& Bowes (2006) discuss transferability and conclude that Scotland is, in general, a good exemplar for the rest of the UK, and offer lessons for transferability. While they seem to hint, following their broadly positive evaluation of Scotland and transferability, that the rest of the UK should adopt FPC, they stop short of providing an outright recommendation. As above, the terms of reference or focus or objectives of Audit Scotland (2008) and Sutherland (2008) do not require a recommendation in the sense of lessons.

Glendinning \& Bell (2008) provide an implicit recommendation, pointing out that virtually no other country restricts access to publicly funded social care to poorer people. Glendinning \& Moran's (2009) final chapter draws out the implications and lessons for reforming adult care and suggests a number of principles for the reform of care and support in England: a
Policy transfer and long-term care in England 
FREP 1,1

major role for the central government, and a single, integrated funding stream for LTC. They continue that income-related insurance contributions (or hypothecated taxation) may be an acceptable, progressive and a way of raising revenue; and argue that design systems in which older and younger disabled people enjoy the same entitlements and benefits are possible.

McCormick et al. (2009) do not provide any recommendations beyond the observation that the Scottish executive was arguably braver than the other UK administrations in its introduction of FPNC. Without producing a clear recommendation, the OECD (2011) suggests the desirability of moving toward universal LTC benefits, irrespective of the financing model. However, it stresses that this does not mean that all LTC should be free. Targeting care benefits where needs are the highest is desirable, even in universal systems, and several countries seem to be moving toward such "targeted universalism," although from different starting points and with very different rates.

Despite suggesting some policy lessons, Bell \& Bowes (2012) do not appear to provide a clear recommendation. The King's Fund Interim Report (2014) is critical of the existing English settlement and urges England to move toward a single ring-fenced budget for health and social care. However, this does not appear to be based on any comparative evidence. Indeed, after discussing insurance schemes in Germany, France and Japan, the report has concerns that a social insurance scheme for social care might conflict with its goal of a more seamless health and social care system. Robertson et al. (2014) write that no one country or model of provision emerges as an ideal.

Bottery et al. (2018) argue that providing FPC similar to the Scottish model would require total public spending of $£ 37 \mathrm{bn}$, a funding gap of $£ 14 \mathrm{bn}$ based on current trends. They note that while this route is not in line with the recent focus on a cap and floor approach, it has similarities with the RCLTC 1999, and the 2010 Labour Government. In addition, they point out that the cost is not significantly more than the Conservative cap and floor model.

Curry et al. (2018) suggest the most pertinent elements of the Japanese system for England regardless of the funding model it adopts: public buy-in, a progressive system, being responsive to public concerns, clarity around benefits and contributions, and a process of public engagement.

Table 3 indicates that some sources offer no clear recommendations (e.g. Bell \& Bowes, 2012; Gibson et al., 2003; King's Fund Interim Report, 2014; McCormick et al., 2009; OECD, 2011; RCLTC, 1999a, b). While Robertson et al. (2014) conclude that no one country or model of provision emerges as an ideal, other studies make broad recommendations. For example, Geraedts et al. (2000) argue that US policymakers can profit from observing the German experience. Bell and Bowes (2006) state that Scotland is, in general, a good exemplar for the rest of the UK, but they do not offer an explicit recommendation. Bottery et al. (2018) favor FPC resembling the Scottish model. However, Campbell \& Ikegami (2003) point to Japan as a good model and Curry et al. (2018) suggest some elements of the Japanese system for England, regardless of the funding.

\section{Discussion and conclusions}

The application of the prospective policy transfer criteria, as applied to the studies, is shown in Table 3. It can be seen that the lessons are rather narrow in terms of both the sources of lessons and studies. As shown in Tables 1 and 2, both the reports and cited studies tend to focus on a fairly narrow range of countries, with most of the attention on Germany, Japan, and Scotland. While these represent both social insurance and taxation routes, they exclude a wide range of other countries. This might be reasonable if the justification for choosing these countries was clear. However, as Table 3 sums up, most studies do not provide much in the way of a clear rationale, and those that do generally focus on recent reforms or "convenience" factors. There is little indication that these 
countries were chosen because they performed best or because their lessons were most transferable in terms of either similar problems or institutional settings. As the size and scope (number of countries) vary significantly across the studies, the level of detail necessarily also varies, ranging from large studies on single nations (e.g. 120 pages on Scotland by Bell \& Bowes, 2006; see also Audit Scotland, 2008; Sutherland, 2008) to several nations (e.g. many nations in some 30 pages by Gibson et al., 2003). There is relatively little focus on problems, although common problems, such as population aging, are discussed. Aims, objectives, and goals are scarcely mentioned in some studies. When goals are discussed, they tend to be fairly abstract or high level, such as "socialization of care." This makes assessing policy performance problematic in the exporting nation. More significantly, it is by no means clear that the importing nation may wish to set the same goals. In other words, just because LTC in one country appears successful in achieving goal $\mathrm{X}$, it does not follow that its approach will achieve goal $\mathrm{Y}$ in a different country. This problem of transferability is compounded by differences in settings. Many studies tend not to discuss this issue, partly because in some cases it is not part of the remit (e.g. Audit Scotland, 2008; Sutherland, 2008). Nevertheless, some studies (e.g. Bell \& Bowes, 2006; Glendinning \& Moran, 2009; Robertson et al., 2014) do discuss transferability. Similarly, Bottery et al. (2018) and Curry et al. (2018) note that as England has no history of social insurance for LTC, it may be difficult to transfer the German or Japanese model. Finally, although few studies provide a clear recommendation, some suggest that policymakers should learn from Germany (Geraedts et al., 2000), Japan (Campbell \& Ikegami, 2003; Curry et al., 2018), or Scotland (Bell \& Bowes, 2006; Bottery et al., 2018).

In conclusion, in very broad terms, the studies cited in the reports do not seem to have played a large role in contributing to the recommendations presented in the reports. Moreover, as determined by Mossberger \& Wolman's (2003) prospective policy transfer criteria, it is difficult to draw clear lessons from abroad from the cited studies. Of course, it is perfectly reasonable to design an LTC scheme without any reference to international experience. However, if international evidence is considered, attention must be paid to issues such as the range of countries and the rationale for selecting them, problems, settings, and goals; and policy performance.

\section{References}

Audit Scotland (2008). A review of free personal and nursing care, available at: www.audit-scotland. gov.uk/docs/health/2007/nr_080201_free_personal_care.pdf.

Barker, K. (2014). A New Settlement for Health and Social Care. Final Report. London: King's Fund.

Bell, D., \& Bowes, A. (2006). Lessons from the Funding of long-term Care in Scotland, findings ref: 0036. York: Joseph Rowntree Foundation.

Bell, D., \& Bowes, A. (2012). Free personal care in Scotland, (almost) 10 years on. In Wolf, D., \& Folbre, N. (Eds.), Universal Coverage of Long-Term Care in the United States: Can We Get There From Here?

Bennett, C., \& Howlett, M. (1992). The lessons of learning: Reconciling theories of policy learning and policy change. Policy Sciences, 25, 275-294.

Bottery, S., Varrow, M., Thorlby, R., \& Wellings, D. (2018). A Fork in the Road: Next Steps for Social Care Funding Reform. The Costs of Social Care Funding Options, Public Attitudes to them - and the Implications for Policy Reform. London: The Health Foundation/King's Fund.

Brodsky, J., Habib, J., \& Mizrahi, I. (2000). Long-term Care Laws in Five Developed Countries; A Review. Jerusalem: JDC-Brookdale Institute of Gerontology and Human Development and World Health Organization.
Policy transfer and long-term care in England 
FREP

1,1
Brooks, R., Regan, S., \& Robinson, P. (2002). A New Contract for Retirement. London: Institute for Public Policy Research.

Cabinet Office (1999). Modernising government. London: Cabinet Office.

Cabinet Office (2002). Beyond the Horizon: A Framework for Policy Comparisons. London: Cabinet Office.

Campbell, J., \& Ikegami, N. (2003). Japan's radical reform of long-term care. Social Policy and Administration, 37(1), 21-34.

Curry, N., Castle-Clarke, S., \& Hemmings, N. (2018). What can England Learn From the Long-term Care System in Japan?. Research report. London: Nuffield Trust.

de Jong, M. (2009). Rose's '10 steps': Why process messiness, history and culture are not vague and banal. Policy \& Politics, 37(1), 145-150.

Dickinson, H., \& Glasby, J. (2006). Free Personal Care in Scotland (Background Paper for Wanless Social Care Review). London: King's Fund. available at: https://www.kingsfund.org.uk/ publications/securing-good-care-older-people.

Dilnot, A. (2011). Fairer Care Funding - the Report of the Commission on Funding of Care and Support. London: The Stationery Office.

Drisko, J., \& Maschi, T. (2016). Content Analysis. Oxford: Oxford University Press.

Geraedts, M., Heller, G., \& Harrington, C. (2000). "Germany's long-term care insurance: Putting a social insurance model into practice”. The Millbank Quarterly, 78(3), 375-401.

Gibson, M., Gregory, S., \& Pandya, S. (2003). Long-term Care in Developed Nations: A Brief Overview. Washington: AARP.

Glendinning, C., \& Bell, D. (2008). Rethinking Social Care and Support: What can England Learn from Other Countries. York: Joseph Rowntree Foundation.

Glendinning, C., \& Moran, N. (2009). Reforming Long-term Care: Recent Lessons from Other Countries, Unpublished Research, Social Policy Research Unit. York: University of York.

Glendinning, C., Davies, B., Pickard, L., \& Comas-Herrera, A. (2004). Funding Long-term Care for Older People: Lessons From Other Countries. York: Joseph Rowntree Foundation.

Green, D. (2019). Fixing the Care Crisis. London: CPS.

Grin, J., \& Loeber, A. (2007). Theories of policy learning: Agency, structure, and change. In Fischer, F., Miller, G., \& Sidney, M. (Eds.), Handbook of Public Policy Analysis. Theory, Politics, and Methods. Boca Raton, FL: CRC Press, 201-219.

Heikkila, T., \& Gerlak, A. (2013). Building a conceptual approach to collective learning: Lessons for public policy scholars. Policy Studies Journal, 41(4), 484-512.

Hirsch, D. (2005). Facing the Cost of Long-term Care: Towards a Sustainable Funding System. York: Joseph Rowntree Foundation.

House of Commons Health and Social Care and Housing, Communities and Local Government Committees Long-Term Funding of Adult Social Care (2018). First Joint Report of the Health and Social Care and Housing, Communities and Local Government Committees of Session 201719, HC 768. London: The Stationery Office.

House of Lords Economic Affairs Committee (2019). Social care funding: Time to end a national scandal. 7th Report of Session 2017-19, HL Paper 392. London: The Stationery Office.

Humphries, R. (2013). Paying for Social Care: Beyond Dilnot. London: King's Fund.

Ingold, J., \& Monaghan, M. (2016). Evidence translation: An exploration of policy makers' use of evidence. Policy and Politics, 44(2), 171-190.

Joseph Rowntree Foundation (2006). Paying for Long-term Care. York: Joseph Rowntree Foundation.

King's Fund (2014). A New Settlement for Health and Social Care. Interim Report of the Commission on the Future of Health and Social Care in England. London: The King's Fund. 
Legrand, T. (2012). Overseas and over here: Policy transfer and evidence-based policy-making. Policy Studies, 33(4), 329-348.

Lightfoot, W., Heaven, W., \& Grič, J. (2019). 21st Century Social Care: What's Wrong with Social Care and How We can Fix it. London: Policy Exchange.

McCormick, J., McDowell, E., \& Harris, A. (2009). Policies for Peace of Mind? Devolution and Older Age in the UK. London: IPPR.

Mehta, K. (2002). National policies on ageing and long-term care in Singapore. A case of cautious wisdom?. In Phillips, D., \& Chan, A. (Eds.), Ageing and Long-Term Care. Ottawa: International Development Research Centre.

Mossberger, K., \& Wolman, H. (2003). Policy transfer as a form of prospective policy evaluation: Challenges and recommendations. Public Administration Review, 63(4), 428-441.

OECD (2011). Health Wanted? Providing and Paying for Long-Term Care. Paris: OECD.

Petrie, K., \& Keohane, N. (2018). No Easy Options Exploring the Options for Reforming Social Care Funding and Eligibility. London: Social Market Foundation.

Powell, M., \& Hall, P. (2020). An idea whose time has not yet come: Government positions on longterm care funding in England since 1999". Research, Policy and Planning, 33(3-4), 137-149.

Quilter-Pinner, H., \& Hochlaf, D. (2019). Social Care: Free at the Point of Need. The Case for Free Personal Care in England. London: IPPR.

Richard Humphries, R., Forder, J., \& Fernández, J-L. (2010). Securing Good Care for More People. Options for Reform. London: King's Fund.

Robertson, R., Gregory, S., \& Jabbal, J. (2014). The social care and health systems of nine countries. Background Paper for the Commission on the Future of Health and Social Care in England. London: The King's Fund.

Rose, R. (1991). What is lesson-drawing. Journal of Public Policy, 2(1), 3-30.

Rose, R. (1993). Lesson-drawing in Public Policy: A Guide to Learning Across Time and Space. Chatham, New Jersey, NJ: Chatham House Publishers.

Royal Commission on Long Term Care (1999a). With Respect to Old Age: Long Term Care Rights and Responsibilities. The Sutherland Report, Cm 4192-I. London: The Stationery Office.

Royal Commission on Long Term Care (1999b). Research Volume 1, Chapter 6: Lessons from International Experience. London: The Stationery Office.

Secretary of State for Health (2009). Shaping the Future of care together, $\mathrm{Cm}$ 7673. London: The Stationery Office.

Secretary of State for Health (2012). Caring for our future: Progress report on funding reform, $\mathrm{Cm}$ 8381. London: The Stationery Office.

Sutherland, S. (2008). Independent Review of Free Personal and Nursing Care in Scotland. Edinburgh: The Scottish Government.

Wanless, D., Forder, J., Fernandez, J.-L., Poole, T., Beesley, L., Henwood, M., \& Moscone, F. (2006). Securing Good Care for Older People: Taking a Long-term View. London: King's Fund.

Wenzel, L., Bennett, L., Bottery, S., Murray, R., \& Sahib, B. (2018). Approaches to Social Care Funding: Social Care Funding Options. London: The Health Foundation.

Wolman, H., \& Page, E. (2002). Policy transfer among local governments: An information-theory approach. Governance, 15(4), 477-501.

\section{Further reading}

Chen, L., Zhang, L., \& Xu, X. (2020). Review of evolution of the public long-term care insurance (LTCI) system in different countries: influence and challenge. BMC Health Serv Res, 20, 1057. doi: 10. 1186/s12913-020-05878-z. 
FREP

1,1

118
Dyer, S.M., Valeri, M., Arora, N., Ross, T., Winsall, M., Tilden, D., \& Crotty, M. (2019). Review of International Systems for Long-Term Care of Older People. Flinders University, Adelaide.

OECD (2020). Long-term Care and Health Care Insurance in OECD and Other Countries. Paris: OECD.

\section{Corresponding author}

Martin Powell can be contacted at: m.powell@bham.ac.uk

For instructions on how to order reprints of this article, please visit our website: www.emeraldgrouppublishing.com/licensing/reprints.htm Or contact us for further details: permissions@emeraldinsight.com 